\title{
THE IMPACT OF AEROBIC TRAINING ON SOME BRAIN NEUROTRANSMITTERS AND BRAIN-DERIVED NEUROTROPHIC FACTOR IN ADDICTED WOMEN
}

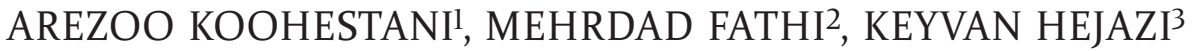 \\ IIslamic Azad University, Department of Sport Sciences, Bojnourd Branch, Bojnourd, Iran \\ 2 Ferdowsi University of Mashhad, Department of Sport Physiology, Mashhad, Iran \\ ${ }^{3}$ Hakim Sabzevari University, Department of Physical Education and Sport Sciences, Sabzevar, Iran
}

\begin{abstract}
Mailing address: Keyvan Hejazi, Hakim Sabzevari University, Department of Physical Education and Sport Sciences, 9617836778 Tohid Shahr, Sabzevar, tel.: +98 (51) 344012620, e-mail: k.hejazi@hsu.ac.ir
\end{abstract}

\begin{abstract}
Introduction. Addiction is a chronic disease that needs time-consuming treatment. The medicines used to stop or reduce the tendency have not been successful so far. The purpose of this study was to investigate the effect of six weeks of aerobic training (morning and afternoon) on some brain neurotransmitters, brain-derived neurotrophic factor and quality of life in addicted females. Material and Methods. Thirty subjects were selected and divided into intervention $(\mathrm{n}=15)$ and control $(\mathrm{n}=15)$ groups. The aerobic training program consisted of six weeks of aerobic training, 3 sessions per week, and each session lasted for 45 to 60 minutes with a maximum intensity of 50-70\% of the maximum heart rate. Paired sample t-test and ANCOVA were used to compare between- and within-group variance changes. Results. Weight levels, body mass index and body fat percentage significantly decreased $(\mathrm{p}<0.05)$, while the serum levels of serotonin, dopamine and brain-derived neurotrophic factor (BDNF) increased significantly. The maximum oxygen consumption and quality of life increased significantly at the end of the period. Changes in intra-group mean in weight, body mass index, body fat percentage, dopamine, BDNF, maximum oxygen consumption, physical limitation, general health, vitality, social activity, physical and emotional function and life satisfaction are significantly different between experimental and control groups $(\mathrm{p}<0.05)$. Conclusions. Six-week aerobic training performed in the morning and afternoon reduces body composition indicators and increases brain neurotransmitters, quality of life and maximum oxygen consumption in addicted females. Therefore, it can be effective in improving physical and mental health.
\end{abstract}

Key words: addiction, aerobic training, dopamine, serotonin, brain-derived neurotrophic factor

\section{Introduction}

Drug addiction, also called drug abuse disorder, can lead to a penchant for drugs. According to the definition of the World Health Organization, drug addiction is an acute or chronic poisoning that is harmful to both the individual and society and is the result of using a natural or industrial medicine [1]. There are no exact statistics on the population of addicted women in the country, but according to the results of some studies, women make up about $9.6 \%$ of addicts in the country. The Ministry of Health also reports in its statistics on addicted women that there is one addicted woman for every eight addicted men [2]. On the other hand, according to the officials of the country's prisons, currently, $50 \%$ of female prisoners are in prison due to drugs and addiction, which has also grown in recent years [3]. Repeated drug use causes long-term damage to dopaminergic and serotonergic terminals and reduces the levels of serotonin, dopamine, their receptors and their synthesizing enzymes [4]. It can also affect neurotrophin levels. Neurotrophins are one of the factors affecting the nervous system that play a significant role in the proliferation, maintenance, plasticity, survival and function of nerve cells in the central and peripheral nervous systems. The most important neurotrophin is BDNF, which is essential for the regulation of neural plasticity for function/performance improvement, the structure of neural circuits, learning and memory [5]. Dopamine is a neurotransmitter that is produced in the dopaminergic axon terminal and has a strong effect on brain activity and on regulating motor functions as well as thought, mood and anxiety disorders [6, 7]. Serotonin is made in the serotonergic axon terminal. Its precursor amino acid is tryptophan, and it has seven types of receptors. Serotonin is an indoleamine that regulates mood and initiates sleep. Low serotonin activity is associated with depression, while its high activity is associated with aggressive behaviors [8, 9].

Evidence suggests that training can alter the release amount of many neurotransmitters in the brain. Therefore, training is considered a valuable contributing factor in the treatment of addiction and improving the condition of an addicted patient. It seems that training is one of the most effective and low-cost methods in the treatment of addiction. The results of research have shown that training, similar to addictive drugs, affects the reward system and increases the dopamine level [10, 11]. Training also alters the synthesis and metabolism of the dopaminergic, noradrenergic and serotonergic systems in addicted individuals [12]. Most studies on the effect of aerobic exercises on serotonin and dopamine regarding the issue of addiction have been performed on laboratory models, which have demonstrated the effect of aerobic exercises on reducing the possibility of addiction [13], the use of addictive drugs [14], withdrawal syndrome symptoms [15], and increasing the release rate of serotonin and dopamine during exercise [16].

In summary, according to conflicting reports about the role of training in BDNF and the side effects of drugs in the treatment of addicts, training is a non-pharmacological method that can have an interaction with the dopaminergic reward system. Training activates the same system in the brain that becomes active following the use of drugs, such as cocaine, through their effects on increasing the dopamine level and its receptors. 
Hence, training is a protective method, which prevents relapse to drug use and promotes neurohormonal adaptation. Nevertheless, few studies on the effect of training on reducing drug dependency, especially the lack of these studies on humans, as well as the increasing prevalence and dependency on drugs in the country, necessitates conducting this research. Therefore, the purpose of this study was to evaluate the effect of six weeks of aerobic training performed in the morning and afternoon on some brain neurotransmitters and quality of life of addicted females.

\section{Material and Methods}

This is a quasi-experimental study in which two experimental and control groups were compared with pre-test and post-test. The statistical population of this study included 80 drug addicts who participated in drug addicts training classes anonymously or under pseudonyms. The statistical sample of this study included 30 addicted females in Bojnourd city. In the primary outcome paper, we specified 15 participants per group using $G^{*}$ power 3.1.363 and assuming 1.25 effect size at 0.05 alpha and 0.9 power $[17,18]$. Effect sizes of $0.2,0.5$ and 0.8 were considered as small, medium and large, respectively [19]. Based on the review of the subjects' medical records, they did not meet the inclusion criteria and did not participate in the research.

In the first stage, the subjects became acquainted with the nature and how to cooperate with the research. The inclusion criteria for entering the study were as follows: at least 4-6 months of elapsed time since the quit date or more than two years of elapsed time from the beginning of drug abuse. They were addicted to only one drug (opium) and took $10 \mathrm{mg}$ of methadone daily during their withdrawal period. They were also not allowed to take other drugs such as codeine, morphine and amphetamines. The subjects voluntarily participated in the research based on the research conditions and signed the consent form. Afterwards, using simple randomization, they were assigned to intervention $(n=15)$ and control $(n=15)$ groups.

The following body composition measurements were made: the height of the subjects was measured with Seca (made in Germany) with a sensitivity of $5 \mathrm{~mm}$, hip and waist circumferences were taken using a tape measure (Mabis/Japan) with a sensitivity of $5 \mathrm{~mm}$, while weight was recorded using a digital scale produced by a German company called Beurer (PS07-PS06). Body fat percentage was calculated using a body compound determiner (model In-body-720 made in Korea). The body mass index (BMI) was obtained by dividing each participant's weight in kilograms by the square of height in meters. All the measurements were taken while the subjects had abstained from eating and drinking for four hours before the test, and their bladder, stomach, and intestines had been emptied as much as possible. According to the MHRR, variables for each subject were calculated based on Karvonen equation (1) and controlled during an exercise by a heart rate monitor (made in Finland-Polar).

\section{Equation 1: Target heart rate $=[\% 50$ or $\% 70 \times[((220$ - age $)-$ Resting heart rate]] + Resting heart rate}

In order to estimate the maximum oxygen consumption, the subjects were asked to run for 12 minutes at the maximum possible speed or to cover a distance of 2400 meters. Then, according to Equation 2, the maximum oxygen consumption was determined:

\section{Equation 2: Maximum oxygen consumption = Horizontal speed $(\mathrm{m} / \mathrm{min}) \times 0.2+5 / 3$}

In this study, quality of life was assessed based on the SF36 quality of life scale. Today, this scale is the most common tool used to assess quality of life [20]. This scale has 36 items including subscales of physical limitation, psychological, general health, vitality, social activity, physical function, emotional function and life satisfaction. The reliability coefficient of the questionnaire using the retest method and Cronbach's alpha for SF36 quality of life was 0.88 .

In this study, blood samples were collected 24 hours before and 48 hours after the training session. The blood samples were taken between 8 and 10 o'clock in the morning after 10 to 12 hours of fasting, from the left hand vein of each subject sitting and resting. To determine the serum amount of dopamine and serotonin by ELISA method and by LDN kit (made in Germany, coefficient of endometrial and exogenous changes of dopamine 14.2 and 22.5 and for serotonin 10.4 and 9.7) and by STAT FAX made in the United States. To measure brain-derived neurotrophic factor, German-made ZellBio kit by ELISA method was used.

The training program consisted of six weeks of aerobic training, 3 sessions per week, and each session (morning and afternoon) for 45 to 60 minutes with a maximum intensity of $50-70 \%$ of the maximum heart rate reserve and training session time gradually increased from 30 minutes at the beginning to 45 minutes at the end of the course. The training program included a general warm-up for 10 minutes (walking, jogging, stretching and mobility); the training intensity was controlled by a POLAR / Finnish pacemaker [21]. The aerobic exercise program during the training period included the aerobic walking exercise, butterfly aerobics, butt kicks and aerobics space skiing. At the end of each session, the training was performed for 10 minutes, returning the body to its original position and cooling down (slow running, walking, and stretching). At the end of the course (after 6 weeks), like pre-test conditions, all measurements and data were collected again (Tab. 1). Also, the control group had no activity during the research period and was inactive and underwent hemodialysis treatment (as before the present study, they had an inactive lifestyle).

Table 1. The details of the training program during six weeks

\begin{tabular}{|c|c|c|c|c|c|c|}
\hline Weeks & 1 & 2 & 3 & 4 & 5 & 6 \\
\hline Duration (min) & 30 & 33 & 36 & 39 & 42 & 45 \\
\hline Intensity (\%) & 50 & 55 & 55 & 60 & 65 & 70 \\
\hline
\end{tabular}

The data were analyzed by SPSS 16 Software. Moreover, normality was assessed using the Shapiro-Wilk test. Afterward, variance homogeneity was checked with Levene's test; next, paired sample t-test and ANCOVA were used to compare between- and within-group variance changes. A level of $5 \%$ was considered statistically significant.

\section{Results}

Table 2 shows the characteristics of the experimental and control subjects. Based on Table 3, at the end of the six-week aerobic training, within-group mean changes in weight (Intervention: $C V=4.8 \%$ and control: $C V=7.8 \%(95 \% C I=0.59-1.52)$; BMI (Intervention: $\mathrm{CV}=8.3 \%$ and control: $\mathrm{CV}=7.7 \%(95 \% \mathrm{CI}$ $=0.21-0.54$ ); BFP (Intervention: $\mathrm{CV}=11.3 \%$ and control: $\mathrm{CV}=$ 
Table 2 . The characteristics of the study participants

\begin{tabular}{|c|c|c|c|c|c|}
\hline \multirow{2}{*}{ Groups } & \multicolumn{5}{|c|}{ Variations (Means \pm SD) } \\
\cline { 2 - 6 } & $\begin{array}{c}\text { Age } \\
(\text { year })\end{array}$ & $\begin{array}{c}\text { Height } \\
(\mathrm{cm})\end{array}$ & $\begin{array}{c}\text { Weight } \\
(\mathrm{kg})\end{array}$ & $\begin{array}{c}\text { BMl } \\
(\mathrm{kg} / \mathrm{m} 2)\end{array}$ & $\begin{array}{c}\text { Body fat } \\
\text { percent }(\%)\end{array}$ \\
\hline \multirow{3}{*}{ Intervention } & $29.53 \pm$ & $166.40 \pm$ & $66.93 \pm$ & $24.23 \pm$ & $18.84 \pm$ \\
& 6.43 & 4.30 & 3.23 & 1.95 & 2.00 \\
\hline \multirow{2}{*}{ Control } & $30.4 \pm$ & $167.46 \pm$ & $70.53 \pm$ & $25.16 \pm$ & $20.32 \pm$ \\
& 5.62 & 3.68 & 5.27 & 1.88 & 2.55 \\
\hline & $p=0.408$ & $p=0.146$ & $p=0.436$ & $p=0.606$ & $p=0.746$ \\
\hline
\end{tabular}

* - P-Value $=$ Normality of data before intervention.

13.1\% (95\% CI = 0.37-2.12) decreased significantly; however, in the experimental group, unlike the control group. Moreover, the levels of Serotonin (Intervention: $\mathrm{CV}=9.6 \%$ and control: $\mathrm{CV}=8.1 \%$ (95\% CI $=-25.58-8.14)$; Dopamine (Intervention: CV $=6.8 \%$ and control: $\mathrm{CV}=4.5 \%(95 \% \mathrm{CI}=-11.88-4.91)$; BDNF (Intervention: $\mathrm{CV}=10.8 \%$ and control: $\mathrm{CV}=8.6 \%(95 \% \mathrm{CI}=$ -1.41-0.51) at the end of the six-week aerobic training increased significantly $(\mathrm{P}<0.05)$; the maximal oxygen consumption (Intervention: $C V=8.8 \%$ and control: $C V=10.6 \%(95 \% C I=-6.80-$ $1.73)$ at the end of the period increased significantly $(p=0.001)$.

Table 4 shows that at the end of the training period, intra-group mean changes concerning physical restraints $(p=0.001)$, psychological health $(p=0.001)$, general health $(\mathrm{p}=0.001)$, vital force $(\mathrm{p}=0.002)$, social activity $(\mathrm{p}=0.001)$, physical performance $(\mathrm{p}=0.001)$, emotional performance $(\mathrm{p}=0.001)$ and life satisfaction $(\mathrm{p}=0.001)$ increased significantly, but the amount of physical pain $(\mathrm{p}=0.003)$ decreased significantly in addicted women.

Furthermore, the results presented in Tables 3 and 4 show the between-group mean changes in the variables of weight $(\mathrm{p}=0.001)$, body mass index $(\mathrm{p}=0.001)$, body fat percentage $(\mathrm{p}=0.005)$, maximal oxygen consumption $(\mathrm{p}=0.01)$, physi- cal restraint $(p=0.001)$, general health $(p=0.001)$, vital force $(p=0.004)$, social activity $(p=0.001)$, physical performance $(\mathrm{p}=0.001)$, emotional performance $(\mathrm{p}=0.001)$ and life satisfaction $(\mathrm{p}=0.001)$.

\section{Discussion}

The results of the present study show that aerobic training leads to a significant increase in serum levels of the brain-derived neurotrophic factor. The results of the present study are consistent with the findings of Schmolesky et al. [22] but not with those of Zare Mehrjardi et al. [23] and Jung et al. [24]. Jung et al. [24] reported a significant inverse relationship between serum BDNF and relative $\mathrm{VO} 2 \mathrm{max}$ and heart rate reserve in men with the age range of 20-76 years. Furthermore, Nofuji et al. [25] found an inverse correlation between serum BDNF and habitual physical activity and suggested a possible explanation in which circulating BDNF may play a role in regulating and/ or maintaining energy metabolism. However, the sample size of the study by Nofuji et al. was small and the potential role of circulating BDNF in energy metabolism needs to be examined in additional studies. Fundamental and exact mechanisms that can demonstrate the beneficial effects of training on brain function and structure are not yet fully understood. However, they can be attributed to the reduction of oxidative stress and inflammation, increased angiogenesis, secretion of neurotrophins and catecholamines, and neurogenesis, especially in the structure of the hippocampus [26]. Physical activity has a positive effect on cognitive function by increasing the level of BDNF protein and essential neurotrophins [27]. BDNF regulates a number of processes, including the growth and function of nerve cells, by performing its role through the tyrosine kinase B receptor. In addition, it promotes the growth of immature nerve cells and contributes to the survival of the adult ones [28]. The effect of training on genes encoding neurotrophins and other plasticity strengthens the suspicion that exercising can support structur-

Table 3. The variation of body composition, brain neurotransmitters and brain-derived neurotrophic factor levels in addicted women

\begin{tabular}{|c|c|c|c|c|c|}
\hline \multirow{3}{*}{ Variables } & \multirow{3}{*}{ Groups } & \multicolumn{4}{|c|}{ Variations } \\
\hline & & \multicolumn{2}{|c|}{ Stages } & P-Value** & P-Value $e^{* * *}$ \\
\hline & & Pre-test (mean $\pm \mathrm{SD}^{*}$ ) & Post-test (mean \pm SD*) & $P$ & $P$ \\
\hline \multirow{2}{*}{ Weight $(\mathrm{kg})$} & Intervention & $66.93 \pm 3.23$ & $65.89 \pm 3.13$ & $0.001 \ddagger$ & \multirow{2}{*}{$0.001 \ddagger$} \\
\hline & Control & $70.53 \pm 5.27$ & $70.55 \pm 5.48$ & 0.91 & \\
\hline \multirow{2}{*}{ BMI (kg/m2) } & Intervention & $24.23 \pm 1.95$ & $23.86 \pm 1.97$ & $0.001 \ddagger$ & \multirow{2}{*}{$0.001 \ddagger$} \\
\hline & Control & $25.16 \pm 1.88$ & $25.16 \pm 1.94$ & 0.92 & \\
\hline \multirow{2}{*}{ BFP $(\%)$} & Intervention & $18.84 \pm 2.00$ & $17.96 \pm 2.03$ & $0.001 \ddagger$ & \multirow{2}{*}{$0.005 \ddagger$} \\
\hline & Control & $20.32 \pm 2.55$ & $20.68 \pm 2.69$ & 0.34 & \\
\hline \multirow{2}{*}{ Serotonin (ng/mL) } & Intervention & $249.13 \pm 22.39$ & $263.53 \pm 25.38$ & $0.001 \ddagger$ & \multirow{2}{*}{$0.001 \ddagger$} \\
\hline & Control & $251.80 \pm 18.95$ & $249.33 \pm 20.29$ & 0.42 & \\
\hline \multirow{2}{*}{ Dopamine (pg/mL) } & Intervention & $86.46 \pm 4.08$ & $95.00 \pm 6.45$ & $0.001 \ddagger$ & \multirow{2}{*}{$0.001 \ddagger$} \\
\hline & Control & $90.00 \pm 4.15$ & $90.13 \pm 4.06$ & 0.70 & \\
\hline \multirow{2}{*}{ BDNF (ng/mL) } & Intervention & $6.17 \pm 0.46$ & $7.23 \pm 0.78$ & $0.001 \ddagger$ & \multirow{2}{*}{$0.005 \ddagger$} \\
\hline & Control & $6.39 \pm 0.63$ & $6.48 \pm 0.55$ & 0.37 & \\
\hline \multirow{2}{*}{$\mathrm{Vo}_{2 \max }(\mathrm{ml} / \mathrm{kg} / \mathrm{min})$} & Intervention & $44.13 \pm 3.85$ & $47.00 \pm 4.15$ & $0.01 \ddagger$ & \multirow{2}{*}{$0.01 \ddagger$} \\
\hline & Control & $47.20 \pm 4.73$ & $45.80 \pm 4.84$ & 0.07 & \\
\hline
\end{tabular}

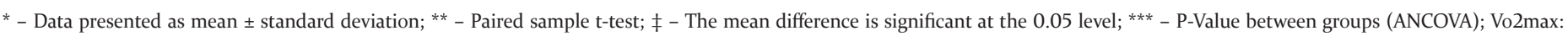
Maximum rate of oxygen consumption; BMI: Body mass index; BFP: Body fat percent; BDNF: Brain-derived neurotrophic factor. 
Table 4 . The variation of lifestyle in addicted women

\begin{tabular}{|c|c|c|c|c|c|}
\hline \multirow{3}{*}{ Variables } & \multirow{3}{*}{ Groups } & \multicolumn{4}{|c|}{ Variations } \\
\hline & & \multicolumn{2}{|c|}{ Stages } & P-Value** & P-Value*** \\
\hline & & Pre-test (mean \pm SD*) & Post-test (mean \pm SD*) & $\mathrm{P}$ & $\mathrm{P}$ \\
\hline \multirow{2}{*}{ Physical restraints } & Intervention & $68.46 \pm 4.76$ & $73.93 \pm 4.25$ & $0.001 \ddagger$ & \multirow{2}{*}{$0.001 \ddagger$} \\
\hline & Control & $70.33 \pm 4.04$ & $69.40 \pm 3.73$ & 0.39 & \\
\hline \multirow{2}{*}{ Physical pain } & Intervention & $73.33 \pm 1.71$ & $72.60 \pm 1.99$ & $0.003 \ddagger$ & \multirow{2}{*}{0.342} \\
\hline & Control & $70.40 \pm 3.06$ & $71.46 \pm 3.92$ & 0.30 & \\
\hline \multirow{2}{*}{ Psychological } & Intervention & $70.40 \pm 0.91$ & $71.40 \pm 0.98$ & $0.001 \ddagger$ & \multirow{2}{*}{$0.003 \ddagger$} \\
\hline & Control & $70.20 \pm 1.42$ & $70.06 \pm 1.38$ & 0.83 & \\
\hline \multirow{2}{*}{ General health } & Intervention & $53.00 \pm 1.96$ & $55.86 \pm 2.50$ & $0.001 \ddagger$ & \multirow{2}{*}{$0.001 \ddagger$} \\
\hline & Control & $55.00 \pm 2.32$ & $54.73 \pm 3.99$ & 0.70 & \\
\hline \multirow{2}{*}{ Vital force } & Intervention & $61.73 \pm 2.84$ & $64.33 \pm 3.13$ & $0.002 \ddagger$ & \multirow{2}{*}{$0.004 \ddagger$} \\
\hline & Control & $62.20 \pm 2.90$ & $61.46 \pm 3.20$ & 0.39 & \\
\hline \multirow{2}{*}{ Social activity } & Intervention & $81.20 \pm 2.17$ & $83.60 \pm 2.09$ & $0.001 \ddagger$ & \multirow{2}{*}{$0.001 \ddagger$} \\
\hline & Control & $80.86 \pm 2.35$ & $80.80 \pm 2.51$ & 0.86 & \\
\hline \multirow{2}{*}{ Physical performance } & Intervention & $80.80 \pm 4.79$ & $86.13 \pm 4.25$ & $0.001 \ddagger$ & \multirow{2}{*}{$0.001 \ddagger$} \\
\hline & Control & $81.20 \pm 4.36$ & $82.80 \pm 4.10$ & 0.10 & \\
\hline \multirow{2}{*}{ Emotional performance } & Intervention & $83.33 \pm 3.03$ & $88.13 \pm 2.87$ & $0.001 \ddagger$ & \multirow{2}{*}{$0.001 \ddagger$} \\
\hline & Control & $81.93 \pm 4.86$ & $81.06 \pm 4.43$ & $0.001 \ddagger$ & \\
\hline \multirow{2}{*}{ Life satisfaction } & Intervention & $71.86 \pm 2.03$ & $75.80 \pm 2.59$ & $0.001 \ddagger$ & \multirow{2}{*}{$0.001 \ddagger$} \\
\hline & Control & $73.26 \pm 2.37$ & $72.73 \pm 2.71$ & 0.16 & \\
\hline
\end{tabular}

* - Data presented as mean \pm standard deviation; ** - Paired sample t-test; $\ddagger$ - The mean difference is significant at the 0.05 level; *** - P-Value between groups (ANCOVA).

al and plastic changes of brain neurons [29]. Physical activity enhances the number of new neurons in the hippocampus and dentate gyrus in animals [30]. Neurotrophic factors such as BDNF and insulin-like growth factor mediate such effects. Physical activity raised BDNF levels in the dentate gyrus, where hippocampal progenitor cells are located, and caused the differentiation and survival of new neurons [31]. Training raises the production/secretion of insulin-like growth factor as well as the factor capable of differentiating progenitor cells in blood circulation by the brain, through which it is able to increase hippocampal BDNF gene expression [32]. After training, there will be a rise in the proliferation stimulating factor and differentiation of neuronal progenitor cells in hippocampal astrocytes [33].

The results of the present study indicated that the serum levels of serotonin and dopamine increased significantly by doing aerobic training. Training activates a number of factors contributing to neurogenesis and cell formation, which alleviates the damage caused by drug use and increases dopamine [34]. Aerobic training boosts intravascular endothelial growth and helps repair drug-induced damage by stimulating angiogenesis and directly affecting the neurotrophic growth factor, which regenerates and restores damaged dopaminergic terminals. Moreover, training has strengthening effects on the reward system [35]. Physical activity brings about more dopamine release when accompanied by cognitive activity and learning $[36,37]$. On the other hand, training increases the activity of endogenous antioxidant enzymes [38]. According to the mentioned mechanisms, aerobic training can increase dopamine. The basis of dopamine release in dopaminergic neurons is a process dependent on nerve impulse. Stimulation of the ventral tegmental nucleus releases dopamine in the nucleus accumbens and has rewarding and dopamine-increasing effects [39]. Probably, these rewarding effects provide sufficient pleasure during training such that the addicted person does not feel the repeated need for drug use. Two-thirds of dopamine neurons are located in the ventral tegmentum, and most dopamine projections to the nucleus accumbens originate in this area [40]. Training leads to releasing certain neurotransmitters in the brain that relieve physical and mental pain. Most of the research carried out in this area has been focused on running; however, all types of aerobic training bring these benefits. It has been revealed that the effects are exerted on the brain through various mechanisms, including neurogenesis, increased patience and endorphin release [41]. Evidence shows that training can alter the release of many neurotransmitters in the brain, such as dopamine, glutamate, acetylcholine, serotonin and endogenous opioids [42].

According to the results of this study, the quality of life in women addicted to drugs increases significantly. Regular physical activity of addicted women can greatly diminish the destructive effects of addiction on the body, and thereby boost the psychological self-concept of this group of people in the society [43]. One of the most important non-physical advantages of training and physical activity is its social dimension. During training, a person inevitably interacts with other people with whom he or she might have lots of common characteristics. This way, the person feels that he or she is in a group with their friends and is taking part in a useful activity beside them, so he or she will feel less lonely. This process is called socialization, which is one of the multidimensional aspects of life quality [44]. Another psychological benefit of training is improving self-esteem and self-confidence, meaning that one feels he or she is as capable as other people, following sports activities. This way, the 
person's self-confidence will increase. Enjoying a better picture of physical condition and the ability to deal with physical health problems more appropriately are also among the instances that are enriched in a person by physical activity and sports interactions [44]. One of the causes of the discrepancies between the findings of this study and other studies could be the difference in the duration and intensity level of the training of the subjects, as in this study, the training was done both in the morning and in the afternoon, and its intensity was light.

On the other hand, studies have shown that exercise is effective in eliminating negative thoughts and creating positive thoughts and ideas that can make one feel more satisfied with life [45]. Brach et al. reported that exercising (20 to 30 minutes a day) increases role-playing and thus improves the quality of life [45]. According to researchers, through releasing endorphins and lowering cortisol secretion, exercise can have a positive effect on mood [44]. The effect of aerobic and group activities rather than anaerobic and individual activities is greater on mental well-being and happiness [46]. Among the limitations of this study, one may mention the lack of control over lifestyle (the amount of sleep, rest and extracurricular activities), genetic and physiological characteristics and various adaptive responses to physical activity together with the low number of subjects due to some participants' withdrawal from the present study. Performing aerobic training can be one of the factors affecting the changes in brain neurotrophic indices/factors due to physiological changes. Besides, the change of such variables depends on the intensity and duration of training as well as the physical condition of individuals. Therefore, coaches and sports physicians are advised to consider the necessary precautions when designing sports training. Generally, it can be concluded that six-week aerobic training performed in the morning and afternoon reduces body composition indices including weight, body mass index, body fat percentage, and increases serum levels of serotonin, dopamine, brain-derived neurotrophic factor and quality of life index among addicted females. Therefore, it can be used to improve the state of patients with drug problems. It seems that supplementary treatment besides pharmacotherapy is needed because addiction mechanisms are very complex. It is suggested that physicians, nurses, families of addicts and coaches should use aerobic training in the morning and afternoon, possibly as a valuable factor in the treatment of addiction and improving the condition of addicts. However, more research is needed to draw more complete and accurate conclusions and present a reliable strategy in the period of addiction.

\section{Acknowledgments}

The authors are thankful to the participants of this study for their excellent collaborations.

\section{References}

1. Leshner A.I. (1999). Science-based views of drug addiction and its treatment. Jama 282(14), 1314-1316. DOI: 10.1001/ jama.282.14.131

2. Khajedaluee M., Moghadam M.D. (2014). Maternal substance abuse and the child's addiction during adolescence and young adulthood. Iranian Journal of Obstetrics, Gynecology and Infertility 16(52), 1-7.

3. Becker J.B., Hu M. (2008). Sex differences in drug abuse. Frontiers in Neuroendocrinology 29(1), 36-47. DOI: 10.1016/j.yfrne.2007.07.003
4. O’dell S.J., Galvez B.A., Ball A.J., Marshall J.F (2012). Running wheel exercise ameliorates methamphetamine-induced damage to dopamine and serotonin terminals. Synapse 66(1), 71-80. DOI: 10.1002/syn.20989

5. Allen M.S., Greenlees I., Jones M. (2011). An investigation of the five-factor model of personality and coping behaviour in sport. Journal of Sports Sciences 29(8), 841-850. DOI: 10.1080/02640414.2011.565064

6. Klein M.O., Battagello D.S., Cardoso A.R., Hauser D.N., Bittencourt J.C., Correa R.G. (2019). Dopamine: functions, signaling, and association with neurological diseases. Cellular and Molecular Neurobiology 39(1), 31-59. DOI: 10.1007/ s10571-018-0632-3

7. Lewis C.R., Henderson-Smith A., Breitenstein R.S., Sowards H.A., Piras I.S. et al. (2019). Dopaminergic gene methylation is associated with cognitive performance in a childhood monozygotic twin study. Epigenetics 14(3), 310-323. DOI: 10.1080/15592294.2019.1583032

8. Squire H., Youn J., Ellenbroek B.A., Harper D.N. (2020). The role of dopamine D1 receptors in MDMA-induced memory impairments. Neurobiology of Learning and Memory 176, 107322. DOI: 10.1016/j.nlm.2020.107322

9. Daut R.A., Fonken L.K. (2019). Circadian regulation of depression: a role for serotonin. Frontiers in Neuroendocrinology 54(1), 100746. DOI: 10.1016/j.yfrne.2019.04.003

10. Flack K., Pankey C., Ufholz K., Johnson L.A., Roemmich J.N. (2019). Genetic variations in the dopamine reward system influence exercise reinforcement and tolerance for exercise intensity. Behavioural Brain Research 375, 112148. DOI: 10.1016/j.bbr.2019.112148

11. Medrano M.C., Hurel I., Mesguich E., Redon B., Stevens C. (2020). Exercise craving potentiates excitatory inputs to ventral tegmental area dopaminergic neurons. Addiction Biology, el2967. DOI: 10.1111/adb.12967

12. Wei Z.-X., Wu Q., Liu Q.-S., Cheng Y. (2020). Neurotransmitter system aberrations in patients with drug addiction. Journal of Neural Transmission 2(1), 1-10. DOI: 10.1007/ s00702-020-02242-7

13. Miller M., Vaillancourt B.D., Wright Jr M.J., Aarde S.M., Vandewater S.A. (2012). Reciprocal inhibitory effects of intravenous d-methamphetamine self-administration and wheel activity in rats. Drug and Alcohol Dependence 121(12), 90-96. DOI: 10.1016/j.drugalcdep.2011.08.013

14. Lynch W.J., Piehl K.B., Acosta G., Peterson A.B., Hemby S.E. et al. (2010). Aerobic exercise attenuates reinstatement of cocaine-seeking behavior and associated neuroadaptations in the prefrontal cortex. Biological Psychiatry 68(8), 774777. DOI: 10.1016/j.biopsych.2010.06.022

15. Buchowski M.S., Meade N.N., Charboneau E., Park S., Dietrich M.S. (2011Aerobic exercise training reduces cannabis craving and use in non-treatment seeking cannabis-dependent adults. PloS ONE 6(3), el7465. DOI: 10.1371/journal. pone.0017465

16. Meeusen R., De Meirleir K. (1995). Exercise and brain neurotransmission. Sports Medicine 20(3), 160-188. DOI: 10.2165/00007256-199520030-00004

17. Kurowski B.G., Hugentobler J., Quatman-Yates C., Taylor J., Gubanich P.J. et al. (2017). Aerobic exercise for adolescents with prolonged symptoms after mild traumatic brain injury: an exploratory randomized clinical trial. The Journal of Head Trauma Rehabilitation 32(2), 79-89. DOI: 10.1097/ HTR.0000000000000238

18. Aguiar L.T., Britto R.R., Teixeira-Salmela L.F., Martins J.C., Faria Ch.D. (2018). Effects of aerobic training on physical 
activity in people with stroke: protocol for a randomized controlled trial. Trials 19(1), 1-8.

19. Leppink J., O'Sullivan P., Winston K. (2016). Effect size large, medium, and small. Perspectives on Medical Education 5(6), 347-349. DOI: 10.1007/s40037-016-0308-y

20. Utian W.H. (2005). Psychosocial and socioeconomic burden of vasomotor symptoms in menopause: a comprehensive review. Health and Quality of Life Outcomes 3(1), 47. DOI: 10.1186/1477-7525-3-47

21. Moghadam M.G., Hejazi K. (2015). Effect of aerobic training for 8 weeks on c-reactive protein, uric acid and total bilirubin in sedentary elderly women. The Horizon of Medical Sciences 21(2), 81-89. DOI: 10.18869/acadpub.hms.21.2.81

22. Schmolesky M.T., Webb D.L., Hansen R.A. (2013). The effects of aerobic exercise intensity and duration on levels of brain-derived neurotrophic factor in healthy men. Journal of Sports Science E Medicine 12(3), 502-513.

23. Mehrjardi R.Z. (2017). Effect of 8 weeks moderate intensity aerobic exercise on brain derived neurotrophic factor (BDNF) in female athletes. Journal of Physical Activity and Hormones 1(2), 29-38.

24. Jung S.H., Kim J., Davis J.M., Blair S.N., Cho H. (2011). Association among basal serum BDNF, cardiorespiratory fitness and cardiovascular disease risk factors in untrained healthy Korean men. European Journal of Applied Physiology 111(2), 303-311.

25. Nofuji Y., Suwa M., Moriyama Y., Nakano H. (2008). Decreased serum brain-derived neurotrophic factor in trained men. Neuroscience letters 437(1), 29-32. DOI: 10.1016/j.neulet.2008.03.057

26. Abbasi-Kangevari M., Ghamari S., Safaeinejad F., Bahrami S., Niknejad H. (2019). Potential therapeutic features of human amniotic mesenchymal stem cells in multiple sclerosis: immunomodulation, inflammation suppression, angiogenesis promotion, oxidative stress inhibition, neurogenesis induction, MMPs regulation, and remyelination stimulation. Frontiers in Immunology 10, 238. DOI: 10.3389/ fimmu.2019.00238

27. Jablochkova A., Bäckryd E., Kosek E., Mannerkorpi K., Ernberg M. (2019). Unaltered low nerve growth factor and high brain-derived neurotrophic factor levels in plasma from patients with fibromyalgia after a 15 -week progressive resistance exercise. Journal of Rehabilitation Medicine 51(10), 779-787.

28. Zoladz J.A., Pilc J. (2010). The effect of physical activity on the brain derived neurotrophic factor: from animal to human studies. Journal of Physiology and Pharmacology 61(5), 533-41.

29. Cotman C.W., Engesser-Cesar C. (2002). Exercise enhances and protects brain function. Exercise and Sport Sciences Reviews 30(2), 75-79.

30. Kim Y.-P., Kim H., Shin M.S., Chang H.K., Jang M.H. et al. (2004). Age-dependence of the effect of treadmill exercise on cell proliferation in the dentate gyrus of rats. Neuroscience Letters 355(1-2), 152-154. DOI: 10.1016/j.neulet.2003.11.005

31. Griesbach G.S., Hovda D.A., Molteni R., Wu A., Gomez-Pinilla F. (2004). Voluntary exercise following traumatic brain injury: brain-derived neurotrophic factor upregulation and recovery of function. Neuroscience 125(1), 129-139. DOI: 10.1016/j.neuroscience.2004.01.030

32. Carro E., Nuñez A., Busiguina S., Torres-Aleman I. (2000). Circulating insulin-like growth factor I mediates effects of exercise on the brain. Journal of Neuroscience 20(8), 29262933. DOI: 10.1523/JNEUROSCI.20-08-02926.2000

33. Ding Q., Vaynman S., Akhavan M., Ying Z., Gomez-Pinilla F. (2006). Insulin-like growth factor I interfaces with brain-derived neurotrophic factor-mediated synaptic plasticity to modulate aspects of exercise-induced cognitive function. Neuroscience 140(3), 823-833.

34. Molteni R., Ying Z., Gómez-Pinilla F. (2002). Differential effects of acute and chronic exercise on plasticity-related genes in the rat hippocampus revealed by microarray. European Journal of Neuroscience 16(6), 1107-1116. DOI:10.1016/j. neuroscience.2006.02.084

35. Belke T.W., Wagner J.P. (2005). The reinforcing property and the rewarding aftereffect of wheel running in rats: a combination of two paradigms. Behavioural Processes 68(2), 165-172. DOI: 10.1016/j.beproc.2004.12.006

36. Di Liegro C.M., Schiera G., Proia P., Di Liegro I. (2019). Physical activity and brain health. Genes 10(9), 720.

37. Li S., Wu Q., Tang Ch., Chen Z., Liu L. (2020). Exercise-based interventions for internet addiction: neurobiological and neuropsychological evidence. Frontiers in Psychology 11, 1296. DOI: 10.3389/fpsyg.2020.01296

38. Teixeira A.M., Trevizol F., Colpo G., Garcia S.C., Charão M. (2008). Influence of chronic exercise on reserpine-induced oxidative stress in rats: behavioral and antioxidant evaluations. Pharmacology Biochemistry and Behavior 88(4), 465-472. DOI: 10.1016/j.pbb.2007.10.004

39. Mansvelder H.D., McGehee D.S. (2000). Long-term potentiation of excitatory inputs to brain reward areas by nicotine. Neuron 27(2), 349-357. DOI: 10.1016/j.pbb.2007.10.004

40. Garris P.A., Kilpatrick M., Bunin M.A., Michael D., Walker Q.D., Wightman R.M. (1999). Dissociation of dopamine release in the nucleus accumbens from intracranial self-stimulation. Nature 398(6722), 67-69. DOI: 10.1038/18019

41. Michael S. (2002). Changing brain chemistry with intense exercise for drug addiction prevention and recovery. Research Confronts Reality 1(1), 716-51.

42. Hassanlouei F., Tabrizi L.B., Hosseini S.A., Rasoli M.H. (2020). The effect of running on positive and negative slopes on serotonin levels in the hippocampus tissue of rats with Alzheimer's disease. Gene, Cell and Tissue 7(1), 1-10. DOI: $10.5812 /$ gct.97076

43. Asbury E.A., Chandrruangphen P., Collins P. (2006). The importance of continued exercise participation in quality of life and psychological well-being in previously inactive postmenopausal women: a pilot study. Menopause 13(4), 561-567. DOI: 10.1097/01.gme.0000196812.96128.e8

44. Kargarfard M., Dehghani M., Heidari A. (2011). Effect of a period of aquatic exercise therapy on the quality of life, anxiety and depression in patients with hemophilia. Koomesh 12(4), 364-372.

45. Brach J.S., Simonsick E.M., Kritchevsky S., Yaffe K., Newman A.B. et al. (2004). The association between physical function and lifestyle activity and exercise in the health, aging and body composition study. Journal of the American Geriatrics Society 52(4), 502-509.

46. Robertson M.C., Campbell A.J., Gardner M.M., Devlin N. (2002). Preventing injuries in older people by preventing falls: A meta-analysis of individual-level data. Journal of the American Geriatrics Society 50(5), 905-911. DOI: 10.1046/j.1532-5415.2002.50218.x

Submitted: January 21, 2021

Accepted: March 26, 2021 